\title{
Role of HIV-1 Viral Load in Initiating Antiretroviral Therapy
}

\author{
Nayana A. Ingole, Seema M. Kukreja, Preeti R. Mehta
}

Microbiology Department, Seth Gordhandas Sunderdas Medical College \& King Edward Memorial Hospital, Mumbai, India. E-mail:drkseema@gmail.com

Received August $3^{\text {rd }}, 2011$; revised September $10^{\text {th }}, 2011$; accepted September $27^{\text {th }}, 2011$.

\begin{abstract}
Purpose: For commencement of Antiretroviral Therapy (ART), CD4 count and/or WHO clinical staging is used as the guide in India. In western countries along with clinical and immunological criteria, HIV-1 viral load is also used to start the patient on treatment. The present study was conducted to determine the role of viral load in taking decision on ART commencement in HIV-1 infected treatment naïve individuals. Method: A cross sectional study was carried out at the Integrated Counseling and Testing Centre (ICTC) in the Department of Microbiology at a Tertiary care teaching hospital after Institutional Ethics Committee approval. After obtaining written informed consent, HIV-1 infected patients who were clinically asymptomatic, ART naïve, having CD4 count $<250 \mathrm{cells} / \mathrm{mm}^{3}$ and age more than or equal to 15 yrs were enrolled in this study. Blood sample was collected and viral load was estimated by COBAS® TaqMan ${ }^{\circledR}$ HIV-1 Test. Result: During the study period of one year, 8966 HIV-1 infected patients were referred for CD4 count estimation. Of these 1624 patients had CD4 count $<250 \mathrm{cells} / \mathrm{mm}^{3}$ and 405 patients were treatment naïve. Of these 96 (23.70\%) patients were clinically asymptomatic and were enrolled. Of those enrolled, ten (10.41\%) had viral load less than 5000 copies $/ \mathrm{ml}$. Conclusion: Decision to start patient on ART can be made judiciously when viral load is used along with CD4 count estimation.
\end{abstract}

Keywords: Viral Load, CD4 Counts, HIV, Monitoring, ART, Clinically Asymptomatic

\section{Introduction}

In developed countries viral load monitoring along with CD4 count estimation is used to make decision regarding commencement of Antiretroviral Therapy (ART) in an HIV infected individual.

Viral load testing is important as a guide for clinical decision making as regards initiation of treatment, switching to second-line treatment and optimizing the duration of the first-line treatment regimen. In addition, the viral load is a particularly useful tool for monitoring adherence to treatment, performing sentinel surveillance for new infections/seroconversion, and diagnosing HIV infection in children aged $<18$ months [1].

But for developing countries, World Health Organization (WHO) recommends starting ART when CD4 count falls below 350 cells $/ \mathrm{mm}^{3}$ or when patient is in WHO clinical stage III or IV if CD4 testing is not available [2]. National AIDS Control Organization (NACO) recommends initiating therapy when patient is in WHO clinical stage III and IV or when CD4 count $<250$ cells $/ \mathrm{mm}^{3}$ [3].

Although it is a standard practice in high-income countries, determination of the HIV viral load is not recommended in developing countries because of the costs and technical constraints. But as more and more countries establish capacity to provide second-line therapy, and as costs and technological constraints associated with viral load testing decrease, determination of the viral load becomes necessary [1].

Hence, this study was conducted to determine whether performing HIV-1 viral load can lead to better decisions in initiating therapy.

\section{Material and Methods}

A cross sectional study was carried out at the Integrated Counseling and Testing Centre (ICTC) in the department of Microbiology at a Tertiary care teaching hospital. Institutional Ethics Committee approval was obtained prior to commencement of the study. HIV-1 infected patients who were clinically asymptomatic, ART naïve, having CD4 count $<250$ cells $/ \mathrm{mm}^{3}$ and age more than or equal to 15 yrs were enrolled in this study after obtaining written informed consent. HIV-1 viral load was estimated by 
COBAS ${ }^{\circledR}$ TaqMan ${ }^{\circledR}$ HIV-1 test.

\subsection{Estimation of HIV Viral Load}

\section{Principles of the Procedure}

The COBAS ${ }^{\circledR}$ TaqMan ${ }^{\circledR}$ HIV-1 Test is based on three major processes: 1) manual specimen preparation to obtain HIV-1 RNA; 2) automated reverse transcription of the target RNA to generate complementary DNA (cDNA) 3) simultaneous PCR amplification of target cDNA using HIV-1 specific complementary primers, and detection of cleaved dual fluorescent dye-labeled oligonucleotide detection probes that permit quantitation of HIV-1 target amplified product (amplicon) and HIV-1 Quantitation Standard RNA, which is processed, amplified and detected simultaneously with the specimen. The test can quantitate HIV-1 RNA over the range of $47-10,000,000$ copies $/ \mathrm{mL}$.

\subsection{Specimen Collection and Storage}

Three $\mathrm{ml}$ of venous blood sample was collected in EDTA vacutainer from each subject. Within six hours of collection, the sample was centrifuged at $800-1600 \times \mathrm{g}$ for 20 minutes at room temperature to separate the plasma. Separated plasma was transferred into sterile polypropylene screw cap tube and was stored in frozen form at $-70^{\circ} \mathrm{C}$ till further use.

\subsection{Specimen, Control and Reagent Preparation}

1) Frozen plasma specimens were kept at room temperature until completely thawed and were vortexed for 5 10 seconds before use.

2) The reagents were allowed to reach ambient temperature before proceeding. Heating Block(s) were preheated to a temperature of $70^{\circ} \mathrm{C}\left( \pm 2^{\circ} \mathrm{C}\right)$ and water bath to a temperature of $50^{\circ} \mathrm{C}\left( \pm 2^{\circ} \mathrm{C}\right)$ before starting the purification reactions.

3) Batches of 21 samples and 3 controls (High positive control, low positive control and negative control) were processed at a time.

\subsubsection{Reagent Preparation (For 24 Tests)}

Reagent preparation was done under a laminar hood

1) The Inhibitor Removal Buffer was prepared by pipetting $20 \mathrm{ml}$ of $96 \%$ - $100 \%$ ethanol to Inhibitor Removal Buffer (IRB). Mixing was done by inverting 5 - 10 times.

2) The Wash Buffer was prepared by pipetting $80 \mathrm{ml}$ of $96 \%-100 \%$ ethanol to the Wash Buffer (WASH). Mixing was done by inverting $5-10$ times.

3) The Elution Buffer (ELB) was preheated at $70^{\circ} \mathrm{C}$ $\left( \pm 2^{\circ} \mathrm{C}\right)$ in a $2.0 \mathrm{~mL}$ screw-cap microfuge tube. Volume eluted was $4 \mathrm{ml}$.

4) $0.5 \mathrm{ml}$ of the Elution Buffer (ELB) was pipetted into the Carrier RNA (CAR). Mixing was done by inverting; then vortexing was done until all of the Carrier RNA was dissolved.

5) $5.0 \mathrm{ml}$ of the Elution Buffer (ELB) was pipeted into the Proteinase K (PK). Mixing was done by inverting; then vortexing was done until all of the Proteinase K was dissolved.

6) The Lysis/Binding Working Solution was prepared by pipetting the volumes listed in the Table 1 .

- The indicated volume of Lysis/Binding Buffer was added to a clean sterile $50 \mathrm{~mL}$ tube.

- The indicated volume of reconstituted Carrier RNA was added to the tube containing the Lysis/Binding Buffer.

- The HIV-1 QS was vortexed for 3 - 5 seconds and indicated volume of HIV-1 QS was added to the tube containing the Lysis/Binding Buffer and the reconstituted Carrier RNA.

- Mixing was done by inverting 10 - 15 times.

- The indicated volume of reconstituted Proteinase K was added to the tube containing the Lysis/Binding Buffer.

- Mixing was done by inverting 10 - 15 times.

\subsubsection{Specimen and Control Preparation}

Specimen and control preparation was also done under laminar hood.

1) $625 \mu \mathrm{L}$ of Lysis/Binding Working Solution was pippeted into each well of the Lysis Rack (I, transparent).

2) $500 \mu \mathrm{L}$ of specimen or control was pippeted into the appropriate well.

3) After all specimens and controls have been added, mixing was done by vortexing for approximately 10 seconds.

4) The Lysis Rack was incubated in a preheated $50^{\circ} \mathrm{C}$ $\left( \pm 2^{\circ} \mathrm{C}\right)$ water bath for 10 minutes. Lysis Rack was dried after removing from water bath.

5) The Lysis Rack was centifuged for $10-20$ seconds at a setting of $4600 \times \mathrm{g}$ in the micro-titer plate centrifuge.

6) $350 \mu \mathrm{L}$ of isopropanol was pippeted into each well.

7) Specimens were mixed by inverting the rack three times, then vortexing the rack for approximately $10 \mathrm{sec}-$ onds.

8) The Lysis Rack was centrifuged for 10 - 20 seconds

Table 1. Preparation of lysis/binding working solution.

\begin{tabular}{cc}
\hline Reagents & 24 \\
\hline Lysis/Binding Buffer $(\mathrm{mL})$ & 14.0 \\
Carrier RNA $(\mu \mathrm{L})$ & 280 \\
HIV-1 QS $(\mu \mathrm{L})$ & 168 \\
Proteinase K $(\mathrm{mL})$ & 2.8 \\
\hline
\end{tabular}


at a setting of $4600 \times \mathrm{g}$ in the micro-titer plate centrifuge.

9) Opening one well at a time, $750 \mu \mathrm{L}$ of specimen or control mixture was transferred to the corresponding wells of the Filter Tube Rack (II, yellow) with affixed Waste Rack (white).

10) After all specimens or controls have been added, the Filter Tube Rack assembly was centrifuged for 2 minutes at $4600 \times \mathrm{g}$ in the micro-titer plate centrifuge.

11) Opening one well at a time, the remaining specimen or control mixture was transferred to the corresponding wells of the Filter Tube Rack.

12) The Filter Tube Rack assembly was centrifuged for 2 minutes at $4600 \times \mathrm{g}$ in the micro-titer plate centrifuge.

13) The Filter Tube Rack was replaced with a new Waste Rack.

14) $400 \mu \mathrm{L}$ of Inhibitor Removal Buffer (IRB) was pippeted down the side of each well.

15) The Filter Tube Rack assembly was centrifuged for 2 minutes at $4600 \times \mathrm{g}$ in the micro-titer plate centrifuge.

16) $700 \mu \mathrm{L}$ of Wash Buffer (WASH) was pippeted down the side of each well.

17) The Filter Tube Rack assembly was centrifuged for 2 minutes at $4600 \times \mathrm{g}$ in the micro-titer plate centrifuge.

18) The Filter Tube Rack was replaced with a new Waste Rack

19) $700 \mu \mathrm{L}$ of Wash Buffer (WASH) was pippeted down the side of each well.

20) The Filter Tube Rack assembly was centrifuged for 3 minutes at $4600 \times \mathrm{g}$ in the micro-titer plate centrifuge.

21) The Filter Tube Rack was placed onto the Elution Rack (IIIA, blue).

22) $75 \mu \mathrm{L}$ of the prewarmed Elution Buffer (ELB) was pipette onto the center of each filter without touching the filter. The Elution Rack was incubated at room temperature for a minimum of 3 minutes after adding Elution Buffer to the last well.

23) The Filter Tube Rack assembly was centrifuged for 3 minutes at $4600 \times \mathrm{g}$ in the micro-titer plate centrifuge.

24) The Filter Tube Rack was removed from the Elution Rack.

25) The Cover Rack (IIIB, blue) was placed onto the Elution Rack (IIIA, blue).

26) The processed specimens and controls are then used directly for PCR.

\subsubsection{Reagent Preparation}

Reagent preparation was done inside a PCR work station.

1) One vial of HIV-1 MMX and one vial CTM Mn2+ was equilibrated at ambient temperature for 30 minutes.

2) K-carrier was placed in a K-carrier holder.
3) New K-tubes were placed in the K-carrier without touching the sides of the K-tubes.

4) The K-tubes were uncapped using the K-tube Capper.

5) The Working MMX was prepared as follows:

For 24 tests, $170 \mu \mathrm{L}$ of CTM Mn2+ was added to one vial of HIV-1 MMX. Mixing was done inverting 10 times.

6) $50 \mu \mathrm{L}$ of Working MMX was pippeted into each K-tube.

7) $50 \mu \mathrm{L}$ of each processed specimen and control were added to the appropriate K-tube containing Working MMX using a micropipettor with an aerosol barrier or positive displacement tip.

Extracted RNA Reverse transcription, amplification and detection were automatically performed by the $\mathrm{CO}$ BAS ${ }^{\circledR}$ TaqMan ${ }^{\circledR} 48$ Analyzer.

The COBAS $\AA$ TaqMan ${ }^{\circledR} 48$ Analyzer:

1) Determined the Cycle Threshold value $(\mathrm{Ct})$ for the HIV-1 RNA and the HIV-1 Quantitation Standard RNA.

2) Determined the HIV-1 RNA titer based upon the $\mathrm{Ct}$ values for the HIV-1 RNA and HIV 1 Quantitation Standard RNA and the lot-specific calibration coefficients.

3) Determined that the calculated copies $/ \mathrm{mL}$ titer for HIV-1 L (+) C and HIV-1 H (+) C fall within the assigned ranges.

\subsection{Interpretation of Results}

Result was checked for flags and comments to ensure that the run is valid. For a valid run, result for each individual specimen was interpreted as mentioned in Table 2.

\section{Results}

During the study period of one year from April 2009 to March 2010, 8966 HIV-1 infected patients were referred for CD4 count estimation to our ICTC. Of these, 1624 patients had CD4 count $<250$ cells $/ \mathrm{mm}^{3}$ and 405 patients were treatment naïve. Of these $96(23.70 \%)$ patients were clinically asymptomatic and were enrolled (Figure 1). Of the 96 patients enrolled, 58 were males and 38 were females. Ten patients had viral load $<5000$ copies/ml. Of these, eight were females and two were males (Table 3).

\section{Discussion}

CD4 count has been reported to be one of the best surrogate markers for monitoring the progression of HIV infection and low CD4 counts are associated with increased risk of developing AIDS or death [4]. Contrary to this, in our study $23.70 \%$ of patients having CD4 count $<$ 250 cells $/ \mathrm{mm}^{3}$ were asymptomatic. Similar findings have been reported by R. Kannangia et al. (2008) where ten (15.2\%) of the 66 patients in CDC category C with CD4 count $<200$ cells $/ \mathrm{mm}^{3}$ were asymptomatic [5]. Thus 
Table 2. Interpretation of results.

\begin{tabular}{cl}
\hline Titer Result & \multicolumn{1}{c}{ Interpretation } \\
\hline Target Not Detected & $\begin{array}{l}\text { Ct value for HIV-1 above the limit for the assay or no Ct value for HIV-1 obtained. Results reported } \\
\text { as "HIV-1 RNA not detected". }\end{array}$ \\
& $\begin{array}{l}\text { Calculated copies } / \mathrm{mL} \text { were less than the Limit of Quantitation of the assay. Results reported as } \\
\text { "HIV-1 RNA detected less than } 47 \mathrm{HIV}-1 \mathrm{RNA} \text { copies } / \mathrm{mL} \text { ". } \\
\text { Calculated results greater than or equal to } 47 \mathrm{copies} / \mathrm{mL} \text { and less than or equal to } 1.00 \mathrm{E}+07 \mathrm{copies} / \mathrm{mL} \\
\text { are within the Linear Range of the assay. } \\
\text { Calculated copies } / \mathrm{mL} \text { were above the range of the assay. Results reported as "greater than } 1.00 \mathrm{E}+07 \\
\text { HIV-1 RNA copies } / \mathrm{mL} \text { ". }\end{array}$ \\
\hline $1.70 \mathrm{E}+01 \mathrm{C} / \mathrm{mL}$ and $\leq 1.00 \mathrm{E}+07 \mathrm{C} / \mathrm{mL}+07 \mathrm{C} / \mathrm{mL}$ &
\end{tabular}

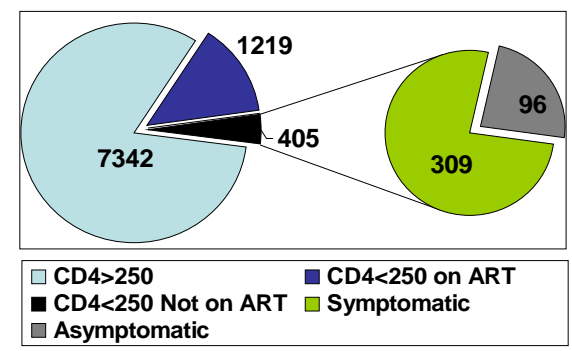

Figure 1. Profile of study population.

Table 3. Distribution of viral load.

\begin{tabular}{cccc}
\hline Viral load (copies $/ \mathrm{ml})$ & Male & female & No of patients \\
\hline$<50$ & 1 & 2 & 3 \\
$50-500$ & 1 & 2 & 3 \\
$500-5000$ & 0 & 4 & 4 \\
$5000-50000$ & 12 & 4 & 16 \\
$50000-500000$ & 27 & 21 & 48 \\
$>500000$ & 17 & 5 & 22 \\
Total & 58 & 38 & 96 \\
\hline
\end{tabular}

discordance between clinical and immunological profile of the patients was observed.

National AIDS Control Organization (NACO) recommends initiating therapy when patient is in WHO clinical stage III and IV or when CD4 count is below 250 cells $/ \mathrm{mm}^{3}$ [3]. In the present study for starting patient on ART, if only clinical criteria were used it could have been misleading.

Starting ART based on immunological criteria has its own limitations. CD4 count is influenced by factors such as age, sex, physical and psychological stress, ethnicity, infection, malnutrition, pregnancy, corticosteroid use, normal diurnal variation, and social isolation [6]. Secondly the mean CD4 count is inherently low in Indian population compared to western population. Also, cut off values of CD4 counts for starting the patient on ART are determined based on findings in western population which may not be appropriate in our settings [7]. The new categories of CD4 counts proposed are cell count $>300$, $81-300$, and $<80$ cells $/ \mathrm{mm}^{3}$ instead of $<500,201-500$, $<200$ cells $/ \mathrm{mm}^{3}$ by R. Kannangia et al. (2008) [5]. Attili VS et al. (2005) have proposed Categories of CD4 counts as $>280,120-280$ and $<$ or $=120$ cells $/ \mathrm{mm}^{3}$ [8]. Thus a separate cut off for CD4 count is recommended for Indian population. Thirdly it has been reported that CD4 count is not a good indicator for predicting viral load [9, 10]. CD4 criteria had a sensitivity of $53.9 \%$, specificity of $76.1 \%$, and the positive predictive value of $44.2 \%$ in detecting virological failure [10].

Considering all these factors viral load has important implications in taking decision on ART commencement.

To start patient on ART based on viral load, there are no recommendations from WHO/British HIV Association (BHIVA).

United States Department of Health and Human Treatment Services/Henry J. Kaiser Foundation recommend starting patient on ART when viral load is $>10,000$ to 20,000 copies per ml or when CD4 cell count is less than 500 cells per $\mathrm{mm}^{3}$ [11]. International AIDS Society-USA Panel recommends starting patient on ART when viral load is more than 30,000 copies per $\mathrm{ml}$ or when CD4+ cell count is less than 350 cells per $\mathrm{mm}^{3}$ and ART is deferred if viral load is less than 5000 copies per ml [11].

Of the 96 patients studied, ten $(10.41 \%)$ patients had viral load less than 5000 copies $/ \mathrm{ml}$.

In resource limited settings like ours where CD4 is used as a guide to start patient on ART, these ten (10.41\%) patients would have been eligible for ART but if viral load is considered then ART can be deferred in these ten patients.

Starting patient on ART is easy but as ART is a lifelong treatment, adherence to therapy is a problem. Adherence rate reported in different studies ranges from $60.4 \%$ to $74.3 \%[12,13]$. ART can also lead to toxicities. Fatu Forna et al. (2005) and Reto Nuesch et al. (2004) have reported toxicities in $39.0 \%$ and $24.2 \%$ of the patients respectively $[14,15]$. Increasing resistance to ART is another issue. In a study by Adge C et al. (2005) 57\% 
of the patient had genotypic resistance to at least one reverse transcriptase inhibitor (RTI) or protease inhibitor (PI) [16]. In Surveillance on HIV antiretroviral drug resistance in treated individuals in England HIV drug resistance reported was 55\% [17].

Hence, for rationale use of ART, viral load can be a better guide compared to CD4 alone. When viral load and CD4 count both are used for predicting progression to AIDS better estimate of risk of progression is provided compared to when either marker is used alone [18]. Also if baseline viral load is available one can monitor the response to treatment by documenting the fall or rise in viral load [11].

Viral load monitoring is significantly superior to CD4 monitoring in assessing viral suppression and treatment failure in patients on ART $[9,10]$ and as clinical failure is an even later development, defining treatment failure on clinical grounds alone is equally suboptimal [1].

Hence, under the National AIDS Control Programme (NACP), the State Reference Laboratories (SRL) can be given the responsibility of performing baseline viral load estimation and monitoring response to therapy especially in case of suspected drug resistance.

In the present study, eight out of 38 females and two out of 58 males had viral load $<5000$ copies $/ \mathrm{ml}$.

In a meta-analysis for gender difference in viral load, Sonia Napravnik et al. (2010) observed that a given population of women have, on average, lower plasma HIV RNA levels compared with a population of men with similar CD4 lymphocyte counts and stage of HIV disease [19]. Shade SB et al. (2000) also observed similar gender differences in viral load. Women with advanced HIV disease have slightly lower levels of viral load than men at corresponding levels of CD4+ cell counts [20].

These gender differences in viral load could necessitate gender specific recommendations for initiation of ART. Hence when HIV-1 RNA thresholds are used to form treatment recommendations for initiating ART, a lower threshold is likely indicated for women compared with men.

To conclude, decision to start patient on ART can be made judiciously when viral load is used along with CD4 count estimation. Also, if baseline viral load value is available it will help in assessing subsequent response to therapy once initiated. Gender differences in viral load necessitate gender specific recommendations for initiation of ART. Virological monitoring should be combined with clinical and immunological monitoring for better patient management.

\section{REFERENCES}

[1] A. Calmy, N. Ford, B. Hirschel, S. J. Reynolds, L. Lynen,
E. Goemaere, F. G. de la Vega, L. Perrin and W. Rodriguez, "HIV Viral Load Monitoring in Resource-Limited Regions: Optional or Necessary?" Clinical Infectious Diseases, Vol. 44, No. 1, 2007, pp. 128-134. doi:10.1086/510073

[2] WHO, "Antiretroviral Therapy for HIV Infection in Adults and Adolescents, Recommendations for a Public Health Approach 2010 Revision," 2010.

http://whqlibdoc.who.int/publications/2010/97892415997 64_eng.pdf

[3] NACO, "Antiretroviral Therapy Guidelines for HIV Infected Adults and Adolescents Including Post Exposure Prophylaxis," Ministry of Health and Family Welfare, 2007.

http://www.nacoonline.org/upload/Policies\%20\&\%20Gu idelnes/1.\%20Antiretroviral\%20Therapy\%20Guidelines $\%$ 20for $\% 20$ HIVInfected $\% 20$ Adults $\% 20$ and $\% 20$ Adolescent s\%20Including\%20Post-exposure.pdf

[4] Y. Pirzada, S. Khuder and H. Donabedian, "Predicting AIDS-Related Events Using CD4 Percentage or CD4 Absolute Counts," AIDS Research and Therapy, Vol. 3, 2006, p. 20. doi:10.1186/1742-6405-3-20

[5] R. Kannangai, A. J. Kandathil, D. L. Ebenezer, G. Nithyanandam, P. Samuel, O. C. Abraham, T. D. Sudarsanam, S. A. Pulimood and G. Sridharan, "Evidence for Lower CD4+ T Cell and Higher Viral Load in Asymptomatic HIV-1 Infected Individuals of India: Implications for Therapy Initiation," Indian Journal of Medical Microbiology, Vol. 26, No. 3, 2008, pp. 217-221. doi: $10.4103 / 0255-0857.42031$

[6] M. Irwin, "Low CD4+ T Lymphocyte Counts: A Variety of Causes and Their Implications to a Multifactorial Model of AIDS," Virusmyth Homepage, 2001. "http://www.virusmyth.com/aids/hiv/milowcd4.htm

[7] K. Ray, S. M. Gupta, M. Bala, S. Muralidhar and J. Kumar, "CD4/CD8 Lymphocyte Counts in Healthy, HIVPositive Individuals \& AIDS Patients," Indian Journal of Medical Research, Vol. 124, 2006, pp. 319-330.

[8] V. S. Attili, S. Sundar, V. P. Singh and M. Rai, "Validity of Existing CD4+ Classification in North Indians, in Predicting Immune Status," Journal of Infection, Vol. 51, No. 1, 2005, pp. 41-46. doi:10.1016/j.jinf.2004.08.022

[9] A. D. Kimmel, M. C. Weinstein, X. Anglaret, S. J. Goldie, E. Losina, Y. Yazdanpanah, E. Messou, K. L. Cotich, R. P. Walensky and K. A. Freedberg, "Monitoring of Antiretroviral Therapy in Resource-limited Settings: Discussion," Journal of Acquired Immunodeficiency Syndrome, Vol. 54, No. 3, 2010, pp. 258-268. doi:10.1097/QAI.0b013e3181d0db97

[10] B. Boughton, "WHO-Mandated CD4 Monitoring for HIV Shows Poor Sensitivity, Specificity," 17th Conference on Retroviruses and Opportunistic Infections (CROI), Abstract 111, San Francisco, 18 February 2010. http://www.medscape.com/viewarticle/717302

[11] E. Mylonakis, M. Paliou and J. D. Rich, "Plasma Viral Load Testing in the Management of HIV Infection," American Family Physician, Vol. 63, No. 3, 2001, pp. 483-490. 
[12] M. B. Cauldbeck, C. O’Connor, M. B O'Connor, J. A. Saunders, B. Rao, V. G. Mallesh, N. Kotehalappa, P. Kumar, G. Mamtha, C. McGoldrick, R. B. S. Laing and K. S. Satish, "Adherence to Anti-Retroviral Therapy among HIV Patients in Bangalore, India," AIDS Research and Therapy, Vol. 6, 2009, p. 7. doi:10.1186/1742-6405-6-7

[13] R. Murri, A. Ammassari, A. De Luca, A. Cingolani, P. Marconi, A. W. Wu and A. Antinori, "Self-Reported Nonadherence with Antiretroviral Drugs Predicts Persistent Condition," HIV Clinical Trials, Vol. 2, No. 4, 2001, pp. 323-329. doi:10.1310/KDM0-RU5W-NVTW-N9MC

[14] F. Forna, C. A. Liechty, P. Solberg, F. Asiimwe, W. Were, J. Mermin, P. Behumbiize, T. Tong, J. T. Brooks and P. J. Weidle, "Clinical Toxicity of Highly Active Antiretroviral Therapy in a Home-Based AIDS Care Program in Rural Uganda," Journal of Acquired Immunodeficiency Syndrome, Vol. 44, No. 4, 2007, pp. 456-462. doi:10.1097/QAI.0b013e318033ffa1

[15] R. Nuesch, P. Srasuebkul, J. Ananworanich, K. Ruxrungtham, P. Phanuphak and C. Duncombe, "Monitoring the Toxicity of Antiretroviral Therapy in Resource Limited Settings: A Prospective Clinical Trial Cohort in Thailand," Journal of Antimicrobial Chemotherapy, Vol. 58, No. 3, 2006, pp. 637-644. doi:10.1093/jac/dk1313

[16] C. Adje, R. Cheingsong-Popov, T. Roels, G. Djomand, et al., "High Prevalence of Genotypic Antiretroviral (ART) Drug-Resistant HIV-1 Strains among HIV-1-Infected Pa- tients Receiving ART in Abidjan, Ivory Coast," Conference on Retroviruses and Opportunistic Infections, San Francisco, 30 January - 2 February 2000.

http://gateway.nlm.nih.gov/MeetingAbstracts/ma?f=1022 43620.html

[17] P. Scott, E. Arnold, B. Evans, A. Pozniak, G. Moyle, M. Shahmenesh, D. White, J. Shirley, P. Cane and D. Pillay, "Surveillance of HIV Antiretroviral Drug Resistance in Treated Individuals in England:1998-2000," Journal of Antimicrobial Chemotherapy, Vol. 54, No. 3, 2003, pp. 469-473.

[18] J. W. Mellors, A. Munoz, J. V. Giorgi, J. B. Margolick, C. J. Tassoni, P. Gupta, L. A. Kingsley, J. A. Todd, A. J. S. R. Detels, J. P. Phair and C. R. Rinaldo Jr., "Plasma Viral Load and CD4+ Lymphocytes as Prognostic Markers of HIV-1 Infection," Annals of Internal Medicine, Vol. 126, 1997, pp. 946-954.

[19] S. Napravnik, C. Poole, J. C. Thomas and J. J. Eron Jr., "Gender Difference in HIV RNA Levels: A Meta-Analysis of Published Studies," Journal of Acquired Immunodeficiency Syndrome, Vol. 31, No. 1, 2002, pp. 11-19. doi:10.1097/01.QAI.0000026906.47530.AB

[20] S. B. Shade, C. Rappoport, D. LeSueur and M. C. Eberly, "Gender Differences in Viral Load: Results from Six Clinical Trials," International Conference on AIDS, Durban, 9-14 July 2000.

http://gateway.nlm.nih.gov/MeetingAbstracts/ma?f=1022 38735.html 